Supplement of Clim. Past Discuss., 11, 5307-5343, 2015

http://www.clim-past-discuss.net/11/5307/2015/

doi:10.5194/cpd-11-5307-2015-supplement

(C) Author(s) 2015. CC Attribution 3.0 License.

(c) (i)

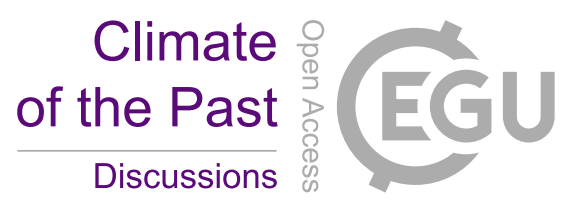

Supplement of

\title{
On the spatial and temporal variability of ENSO precipitation and drought teleconnection in mainland Southeast Asia
}

\section{T. A. Räsänen et al.}

Correspondence to: T. A. Räsänen (timo.rasanen@aalto.fi)

The copyright of individual parts of the supplement might differ from the CC-BY 3.0 licence. 

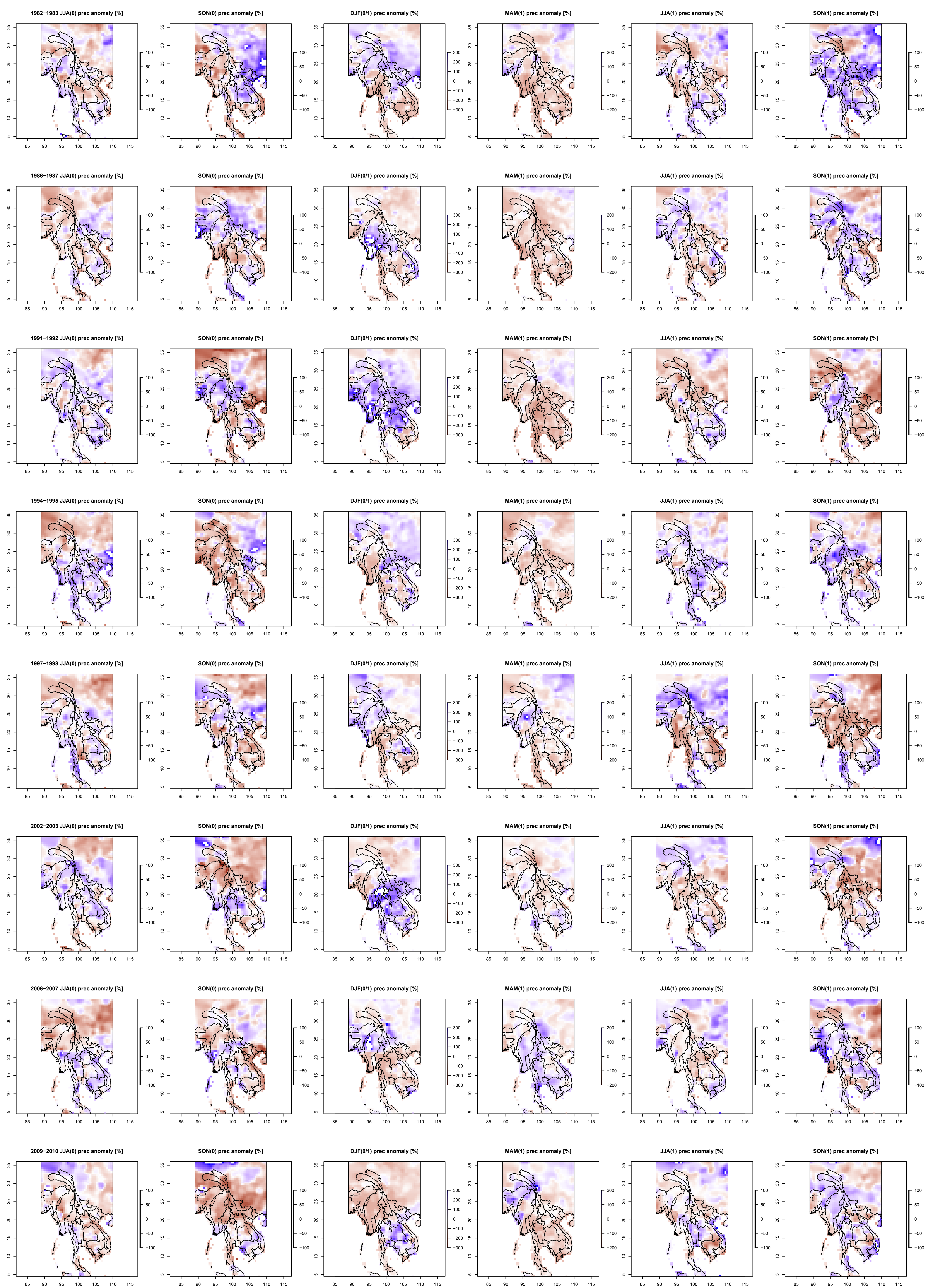

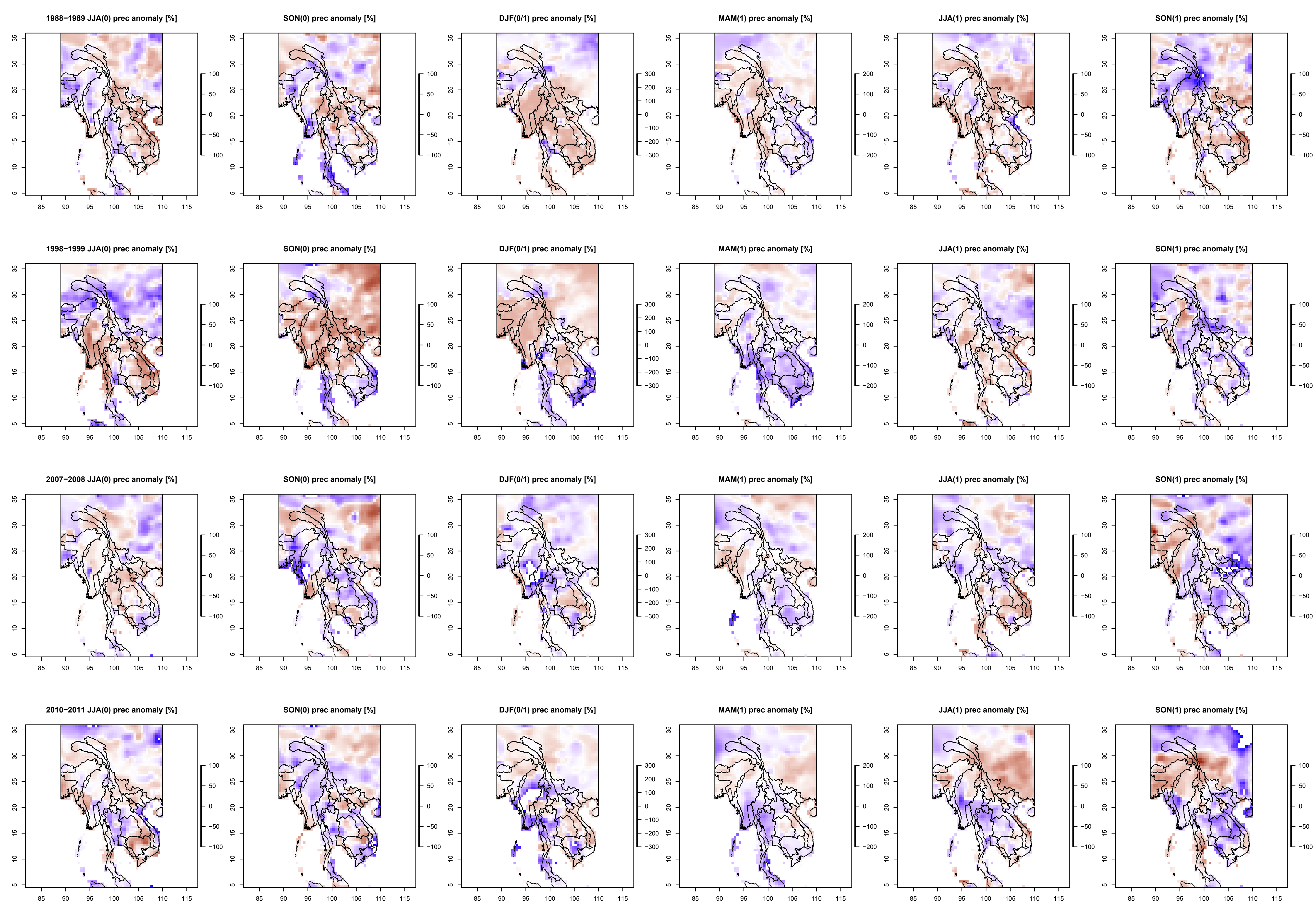

Fig. S2
scale. 